\title{
Komposisi Jenis Udang Air Tawar di Sungai Batambean, Pulau Labobo, Banggai Laut, Sulawesi Tengah, Indonesia
}

\section{(Composition of Freshwater Shrimps in Batambean Stream, Labobo Island, Banggai Laut, Central Sulawesi, Indonesia)}

\author{
Puji Rahayu ${ }^{1 \star}$ dan A. Annawaty ${ }^{1}$ \\ ${ }^{1}$ Lab. Biosistematika Hewan dan Evolusi, Jurusan Biologi, Fakultas MIPA Universitas Tadulako Jl. Soekarno Hatta \\ km 9 Tondo, Palu 94118, Sulawesi Tengah, Indonesia.
}

Keywords: Macrobrachium, Caridina, freshwater shrimp, Labobo isle, Sulawesi

Keywords: Macrobrachium, Caridina, udang air tawar, Pulau Labobo, Sulawesi

${ }^{*}$ Coresponding Author : puiir437@gmail.com

\begin{abstract}
Labobo isle is one of the satellite isle located around the mainland of Sulawesi Island. This study aims to determine the species composition of freshwater shrimp in the Batambean Stream located on Labobo Island, Banggai Laut, Central Sulawesi, Indonesia. A purposive sampling method based on the habitat of freshwater shrimps was applied to collect the shrimps. Measurement of abiotic environmental factors is carried out before samples collection. Furthermore, freshwater shrimp are collected using tray net and hand net. Collected specimens were preserved in alcohol $96 \%$. The specimen wasidentified at the Laboratory of Animal Biosystematics and Evolution, Department of Biology, Faculty of Sciences, Tadulako University. The composition of freshwater shrimp species in the Batambean Stream consists of four species, namely Macrobrachium equidens, $M$. australe, and $M$. latidactylus and Caridina gracilipes. The first three species belong to the family Palaemonidae while the latter species is a member of the family Atyidae. The brief description and conservation status of each species were also provided.
\end{abstract}

\begin{abstract}
Abstrak
Pulau Labobo adalah salah satu pulau kecil yang merupakan bagian dari Pulau Sulawesi. Penelitian ini bertujuan untuk mengetahui komposisi jenis udang air tawar di Sungai Batambean yang berada di Pulau Labobo, Banggai Laut, Sulawesi Tengah, Indonesia. Sampel dikoleksi dengan menggunakan metode purposive sampling berdasarkan lokasi yang menjadi habitat udang air tawar. Pengukuran faktor-faktor lingkungan abiotik dilakukan sebelum koleksi sampel. Spesimen yang diperoleh diawetkan dalam botol yang telah diisi alkohol $96 \%$. Identifikasi spesimen dilakukan di Laboratorium Biosistimatika Hewan dan evolusi Jurusan Biologi FMIPA Universitas Tadulako. Komposisi jenis udang air tawar di Sungai Batambean terdiri dari empat spesies, yaitu Macrobrachium equidens, M. australe, M. latidactylus dan Caridina gracilipes. Tiga spesies pertama termasuk kedalam famili Palaemonidae sedangkan satu spesies terakhir adalah anggota dari famili Atyidae. Dalam tulisan ini disertakan juga deskripsi singkat dan status konservasi masing-masing spesies.
\end{abstract}

\section{Latar Belakang}

Pulau Sulawesi selama ini telah dikenal sebagai kawasan yang menyimpan keanekaragaman fauna dari berbagai kelompok taksa, termasuk udang air tawar.
Berbagai laporan dalam sepuluh tahun terakhir ini memutakhirkan daftar jenis-jenis udang air tawar yang terdapat di perairan lotik maupun lentik Pulau Sulawesi. 
Keseluruhan udang air tawar yang dilaporkan tersebut terbagi ke dalam dua famili yaitu famili Atyidae dan famili Palaemonidae. Anggota famili Atyidae dicirikan oleh adanya capit pada kaki pertama dan kedua yang relatif kecil, pendek dan berukuran sama serta terdapat setae pada bagian ujung chela sebaliknya udang famili Palaemonidae memiliki kaki jalan kedua yang berukuran besar dan panjang serta berkembang dengan baik, pada udang jantan adanya chela akan tumbuh membesar dan memiliki panjang bahkan hampir melebihi panjang tubuhnya (Wowor et al. 2004). Laporan mengenai udang air tawar di Sulawesi, selama ini lebih banyak terfokus di daratan utama (main land), padahal Sulawesi memiliki banyak gugusan pulau-pulau kecil atau pulau satelit yang berada di sekelilingnya yang berpotensi menyimpan keanekaragaman udang air tawar. Tidak banyak catatan mengenai udang air tawar yang ada di pulau satelit di sekitar Pulau Sulawesi, laporan yang telah ada antara lain adalah dari Holthuis (1950) yang melaporkan adanya jenis Macrobrachium sulcicarpale dari Pulau Salajar (sekarang bernama Pulau Selayar). Von Rintelen et al. (2008) juga melaporkan adanya spesies Caridina thomasi dari Pulau Peleng, Banggai Kepulauan.

Salah satu pulau satelit dari Pulau Sulawesi yang menjadi habitat bagi udang air tawar adalah Pulau Labobo, yang terletak di Kabupaten Banggai Laut, Sulawesi Tengah. Pulau ini memiliki banyak sungai yang umumnya adalah sungai kecil yang berasal dari mata air yang berada di pulau tersebut, sehingga penduduk penghuni pulau menamakan sungai sebagai mata air. Sebagian sungai ini, bahkan mengalami kekeringan pada saat musim kemarau tiba, dan hanya akan terisi air kembali pada saat musim penghujan.

Sungai Batambean adalah salah satu sungai di Pulau Labobo yang dihuni oleh udang air tawar (observasi pribadi), namun hingga saat ini tidak ada data ilmiah yang tersedia mengenai spesies udang air tawar apa saja yang terdapat di sungai tersebut, padahal informasi ilmiah mengenai keberadaan biota termasuk udang air tawar di suatu wilayah sangatlah penting sebagai dasar untuk menentukan status konservasi maupun pengelolaan dan pemanfaatan biota tersebut di kemudian hari.

Tulisan ini mengungkapkan mengenai jenis udang air tawar yang terdapat di Sungai Batambean, Pulau Labobo dan status konservasinya yang tercatat dalam International Union for Conservation of Nature and Natural Resources (IUCN).

\section{Bahan dan Metode Bahan dan Alat}

Bahan yang digunakan yaitu alkohol 96\% yang berfungsi untuk mengawetkan udang air tawar, sedangkan alat yang digunakan yaitu mikroskop stereo yang berfungsi untuk identifikasi udang air tawar, tray net sebagai alat pengambilan sampel, termometer sebagai alat mengukur suhu air, DO meter sebagai alat mengukur oksigen terlarut, $\mathrm{pH}$ meter sebagai alat mengukur kadar keasaman, GPS sebagai alat menentukan titik koordinat dan meteran gulung sebagai alat pengukur lebar dan kedalaman sungai.

\section{Metode}

Pengoleksian sampel udang air tawar dilakukan, di Sungai Batambean, Pulau Labobo, Banggai Laut, Sulawesi Tengah, Indonesia (Gambar 1). Sampel dikoleksi menggunakan tray net dengan melihat habitat yang biasanya dihuni oleh udang air tawar seperti di sela tumbuhan air, di balik batu atau di antara serasah daun yang terdeposit di sungai. Pengambilan sampel dilakukan di tiga stasiun yaitu bagian hilir, tengah dan bagian hulu sungai (Gambar 2). Sampel yang diperoleh dipreservasi dengan menggunakan alkohol 96\% dan diberi label lapangan yang meliputi stasiun, substrat, habitat, tanggal dan koleksi dan nama kolektor.

Parameter lingkungan yang diukur meliputi parameter fisik yang terdiri dari suhu dan salinitas, serta parameter kimia yang terdiri dari $\mathrm{pH}$ (derajat keasaman) dan Dissolved Oxygen (oksigen terlarut). Habitat dan substrat tempat ditemukannya udang air tawar juga diamati, meliputi kecepatan arus, serta lebar dan kedalaman sungai.

Identifikasi sampel dilakukan di Laboratorium Biosistematika Hewan dan Evolusi, Jurusan Biologi, FMIPA Universitas Tadulako, menggunakan mikroskop stereo dan mengacu pada literatur Chace dan Bruce (1993) dan Wowor et al., (2004). Spesimen yang telah diidentifikasi selanjutnya disimpan di Laboratorium Biosistematika Hewan dan Evolusi, Jurusan Biologi, Fakultas Matematika dan IImu Pengetahuan Alam Universitas Tadulako.

\section{Hasil dan Pembahasan}

Sungai Batambean berada sangat dekat dengan laut dengan elevasi 10-12 mdpl. Sungai Batambean yang berada di bagian hulu (S $01^{\circ} 40^{\prime} 42,3^{\prime \prime}$ E 123ํำ'28,8") ditumbuhi vegetasi berupa pohon sagu dan semaksemak, sementara bagian hilir (S 0100'45,7" E $\left.123^{\circ} 21^{\prime} 33,7^{\prime \prime}\right)$ yang mendekati muara sungai, bagian tepinya dipenuhi oleh mangrove. Spesies udang air 
tawar yang didapatkan di Sungai Batambean beserta status konservasinya disajikan dalam Tabel 1.

Hasil yang diperoleh menunjuk-kan bahwa spesies udang air tawar di Sungai Batambean lebih didominasi oleh genus Macrobrachium yaitu diperoleh tiga spesies sedangkan genus Atyidae hanya didapatkan satu spesies. Hal ini sejalan dengan Merquet (1991), yang mengatakan bahwa udang air tawar dari famili
Atyidae lebih banyak ditemukan diperairan dataran tinggi dibandingkan dengan udang famili Palaemonidae genus Macrobrachium yang lebih banyak ditemukan di perairan dataran rendah di Kepulauan Marquesas, Kepulauan Tuamotu, Kepulauan Society, Kepulauan Austral dan Kepulauan Gambier.

Tabel 1. Jumlah individu setiap spesies dan status konservasinya

\begin{tabular}{clcc}
\hline Famili & \multicolumn{1}{c}{ Spesies } & Jumlah individu & Status konservasi IUCN \\
\hline Palaemonidae & Macrobrachium equidens & 81 & $L C^{1)}$ \\
& M. australe & 19 & $L C^{1)}$ \\
Atyidae & M. latidactylus & 4 & $L C^{1)}$ \\
Keterangan: ${ }^{1)}$ De Grave et al. $(2013),{ }^{21}$ Cai et al. (2013). & 15 & $L C^{2)}$ \\
\hline
\end{tabular}

Seluruh spesies udang air tawar di Sungai Batambean termasuk dalam kategori Least Concern (LC) berdasarkan IUCN, yang artinya spesies dengan tingkat risiko rendah, yaitu spesies yang telah dievaluasi namun tidak masuk dalam kategori manapun. Spesies-spesies tersebut tidak termasuk ke dalam spesies terancam atau mendekati terancam punah atau ketergantungan konservasi.

Empat spesies ini masih banyak ditemukan atau melimpah di alam karena termasuk spesies yang tersebar secara luas dan bersifat amphidromy. Menurut McDowall (2007), sifat amphidromy dijumpai pada beberapa spesies Crustacea, termasuk udang air tawar. Sifat amphidromy ditandai dengan pelepasan telur oleh induk betina yang akan menetas di air tawar, selanjutnya larva udang akan terbawa oleh arus sungai menuju ke laut atau air payau untuk selanjutnya tumbuh menjadi juvenil dan akan bermigrasi ke air tawar untuk melanjutkan pertumbuhan menjadi udang dewasa.

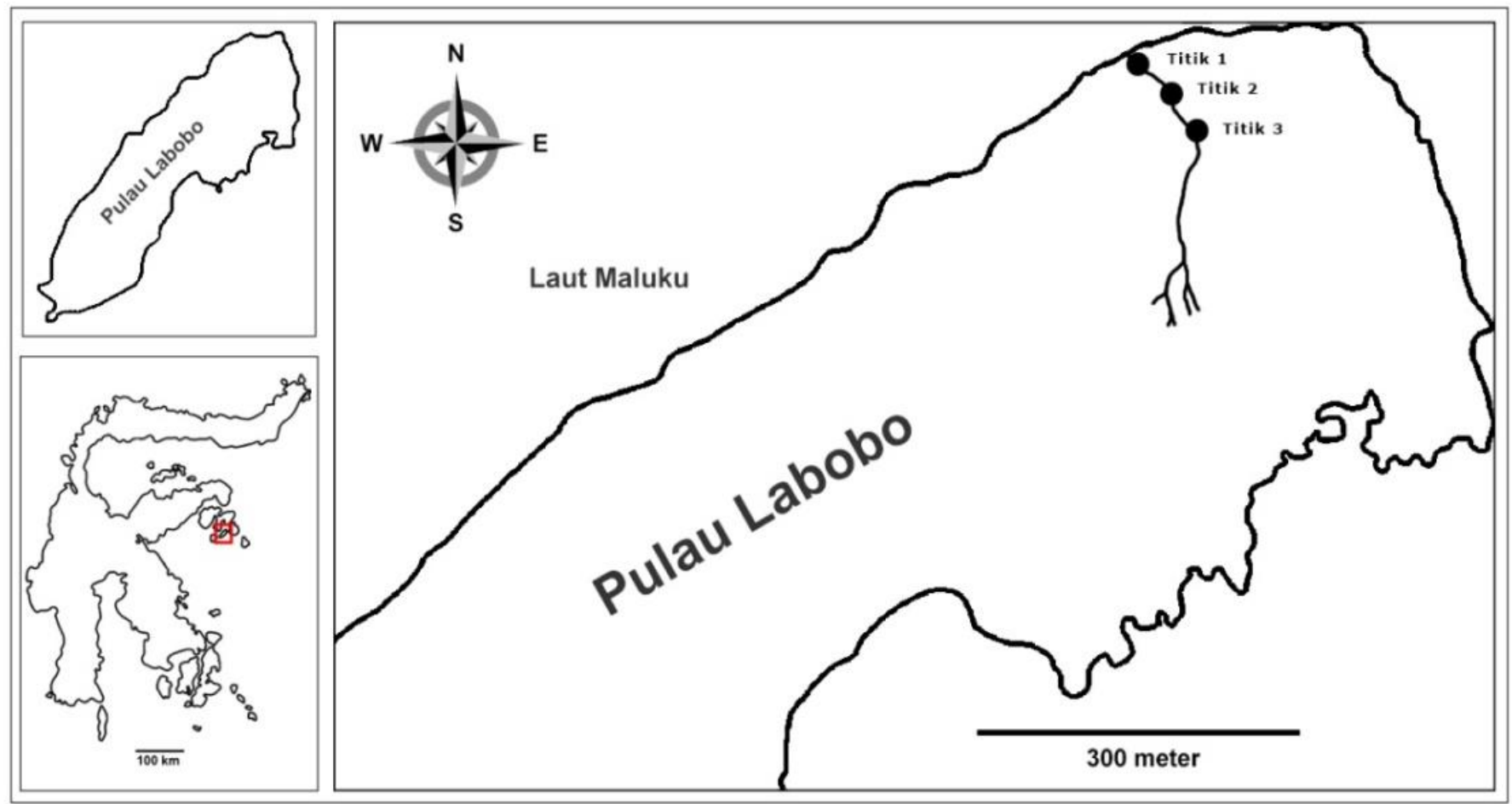

Gambar 1. Peta lokasi penelitian di Sungai Batambean, Pulau Labobo. 


\section{Kondisi Lingkungan}

Parameter lingkungan yang didapatkan di Sungai Batambean yaitu $\mathrm{pH}$ berkisar antara 8,2-8,3. Derajat keasaman yang didapatkan cukup tinggi dan termasuk $\mathrm{pH}$ basa, akan tetapi $\mathrm{pH}$ tersebut masih cukup baik untuk pertumbuhan udang air tawar. Menurut D'Abramo et al., 2006, pH optimum untuk pertumbuhan udang berkisar antara 7-9, akan tetapi pH paling baik untuk pertumbuhan udang yaitu berada pada nilai 7 .

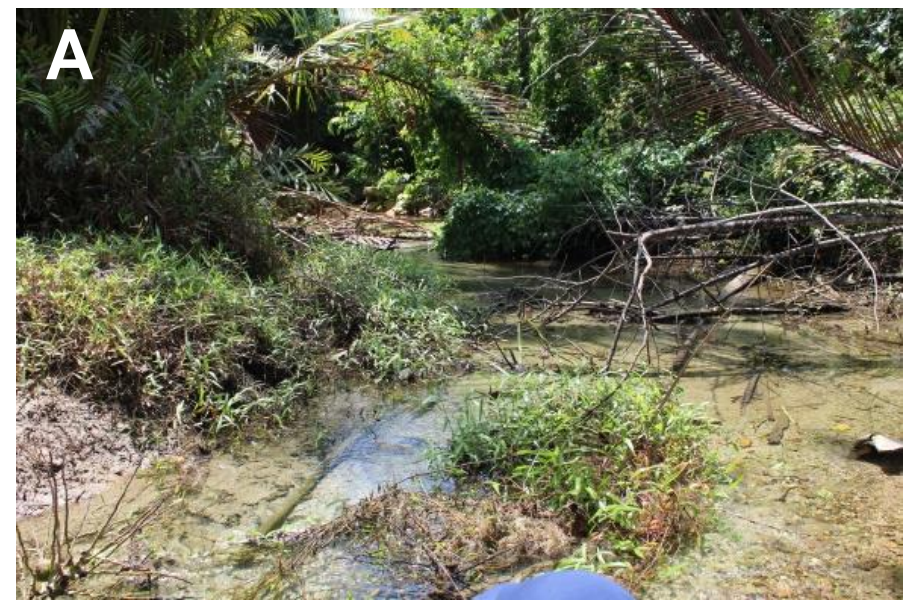

Suhu air di Sungai Batambean dilakukan berkisar antara $27-28^{\circ} \mathrm{C}$. New (2002) menyatakan bahwa suhu yang ideal untuk pertumbuhan udang air tawar berkisar antara $28-311^{\circ} \mathrm{C}$. Suhu yang didapatkan di Sungai Batambean termasuk masih normal untuk pertumbuhan udang air tawar. Selanjutnya kadar oksigen terlarut (DO) yang didapatkan $8,8 \mathrm{ml} / \mathrm{g}$, kisaran yang dilaporkan Valenti et al. (2010), bahwa oksigen terlarut yang baik untuk pertumbuhan udang air tawar yaitu lebih besar daripada $4 \mathrm{ml} / \mathrm{g}$.

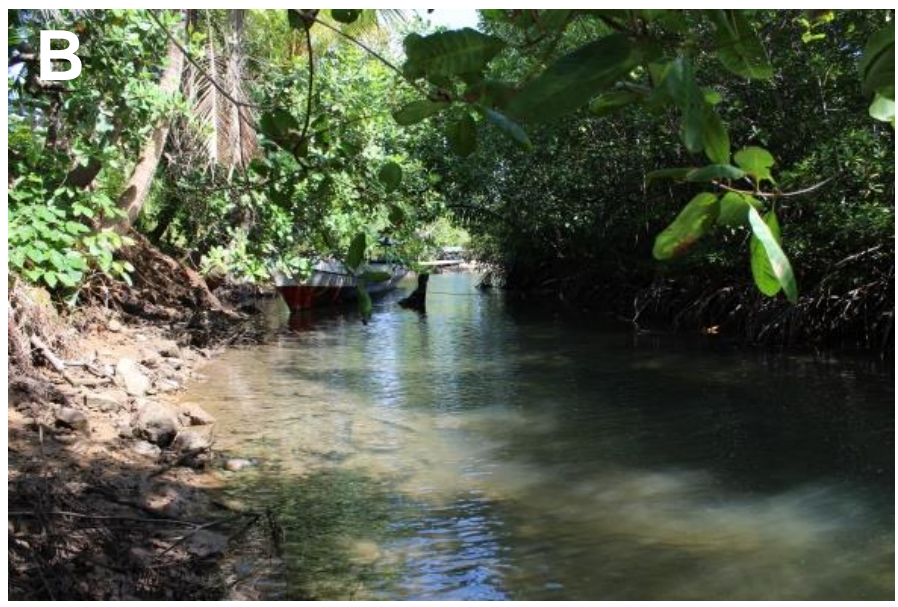

Gambar 2. Lokasi Pengambilan sampel udang air tawar di Sungai Batambean (A) bagian hulu (B) bagian hilir.

Salinitas yang didapatkan pada Sungai Batambean berkisar antara 0-0,5 ppt. Menurut New (2002), salinitas optimal untuk pertumbuhan udang air tawar kurang dari 10 ppt. Sungai Batambean memiliki lebar yaitu $9,5 \mathrm{~m}$ dan kedalaman sungai $25 \mathrm{~cm}$, dengan lebar dan kedalaman demikian serta karena posisi sungai yang sangat landai yang berada di elevasi 212 mdpl membuat arus di Sungai Batambean tergolong sangat lambat yaitu dengan nilai kecepatan 0,029 m/detik. Menurut Welch and Lindell (1980), kecepatan arus yang lebih rendah daripada $0,10 \mathrm{~m} /$ detik dikategorikan sangat lambat. Dengan kondisi arus sungai yang demikian, maka tidak mengherankan apabila di sungai ini ditemukan udang air tawar dari keempat jenis yang telah disebutkan di atas. Udangudang air tawar tersebut memiliki struktur kaki jalan (periopod) yang panjang dan langsing, sehingga sangat sesuai untuk hidup di sungai yang kecepatan arusnya lambat.

Udang air tawar di Sungai Batambean didapatkan dari berbagai habitat, yaitu di bawah serasah daun, di antara kayu lapuk dan di sela-sela tumbuhan air dengan substrat sungai berupa pasir berbatu dan lumpur.

\section{Deskripsi dan Distribusi Spesies}

Empat spesies udang air tawar yang ditemukan di Sungai Batambean (tabel 1) umumnya merupakan spesies yang menghuni perairan yang tenang, hal ini ditunjukkan oleh morfologi kaki jalan ke satu dan kedua yang panjang dan langsing. Deskripsi singkat dari masing-masing spesies adalah sebagai berikut.

\section{Macrobrachium equidens}

Macrobrachium equidens memiliki ciri morfologi berupa gigi rostral dorsal berjumlah 5-10, gigi di belakang mata berjumlah 1-3 dan gigi rostral ventral berjumlah 3-7, memiliki post antenular carapace margin yang tegak lurus atau miring (Gambar 3A). Sepasang kaki jalan kedua yang langsing dengan bentuk sama dan ukuran berbeda (Gambar 3B). Morfologi M. equidens yang didapatkan sesuai dengan yang dideskripsikan Chace and Bruce (1993).

Macrobrachium equidens dilaporkan terdistribusi di daratan utama Sulawesi yaitu dari Makassar, sungai yang berada dekat Palopo, Pare-Pare, Air terjun Bantimurung dan dari Ondolean (Holthuis, 1950).

Macrobrachium equidens adalah spesies yang tersebar luas di dunia, mulai dari Indonesia, India, 
Cina, Filipina, Pulau Solomon, Kepulauan Palau, Afrika Selatan dan Negeria (Chace and Bruce, 1993).

\section{Macrobrachium australe}

Macrobrachium australe memiliki ciri morfologi berupa gigi rostral dorsal berjumlah 2-13, gigi di belakang mata berjumlah 1-3 dan gigi rostral ventral berjumlah $3-5$, sepasang kaki jalan kedua yang langsing dengan bentuk dan ukuran yang berbeda. Morfologi M. australe yang didapatkan di Sungai Batambean sesuai dengan yang dideskripsikan Chace and Bruce, (1993).
Macrobrachium australe pernah dilaporkan dari pulau satelit lainnya yang berada di sekitar Pulau Sulawesi yaitu dari Pulau Talaud dan Pulau Salayar sedangkan laporan yang berada di dataran utama Sulawesi yaitu dari Sungai Tjenrana dekat Pompanuwa (Holthuis, 1950), Sungai Tinombo (Rahmi dkk., 2016) dan Sungai Batusuya (Dwiyanto dkk., 2018).

Spesies ini adalah jenis udang yang tersebar luas di Indo-Pasifik Barat, dari Madagaskar, Polinesia, Seychelles, Taiwan, Indonesia dan Kepulauan Pasifik (Cai and Shokita, 2006; Eguia et al., 2009).

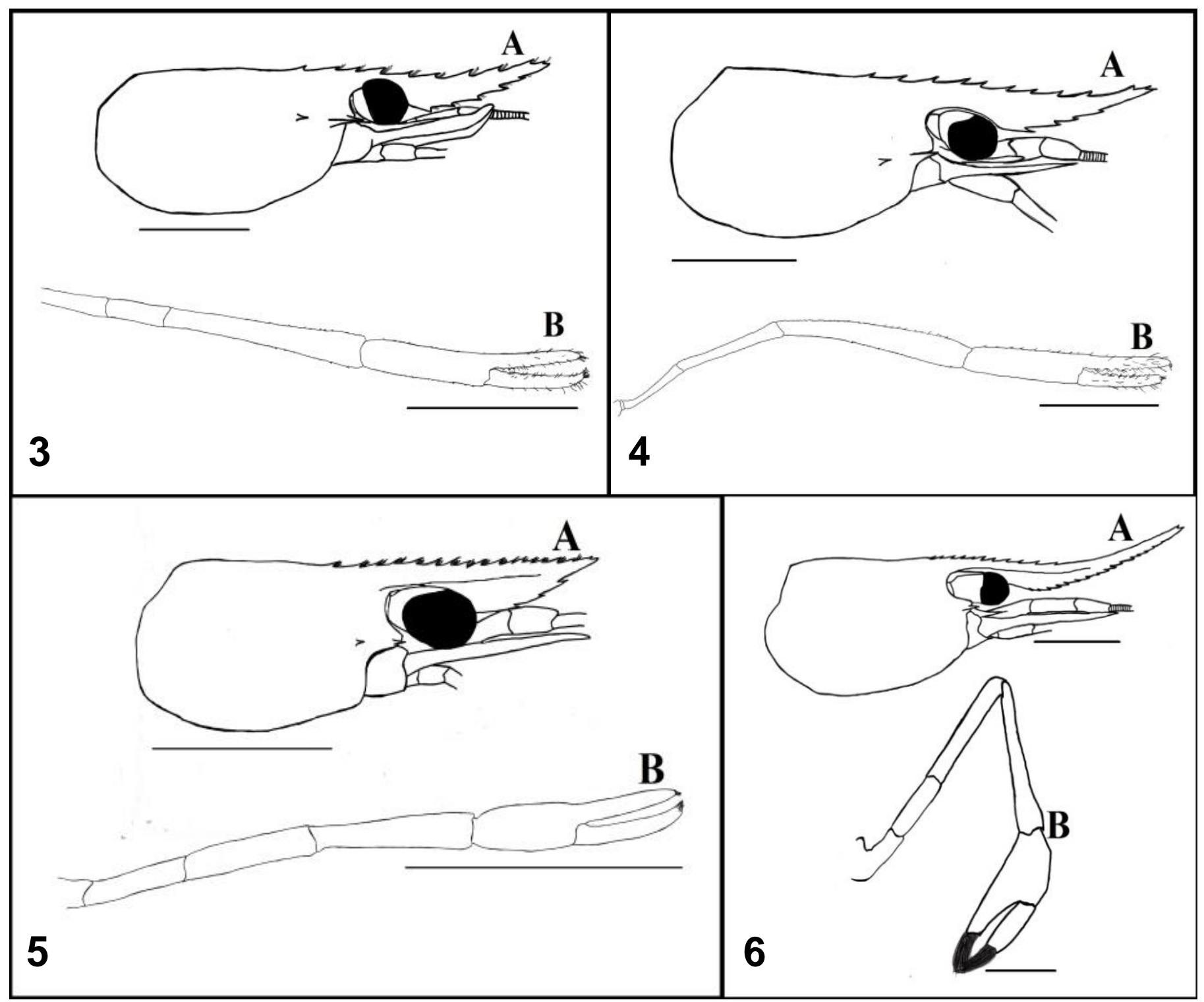

Gambar 3-6. Morfologi udang air tawar yang terdapat di Sungai Batambean, Pulau Labobo: 1. Macrobrachium equidens, 2. Macrobrachium australe, 3. Macrobrachium latidactylus, 4. Caridina gracilipes, A. Carapace, B. Periopod kedua. Skala bar: Gambar 3. A: 0,5 cm, B:0,5 cm; Gambar 4. A: 0,5 cm, B: $1 \mathrm{~cm}$; Gambar 5. A: 0,4 cm, B: 0,5 cm; Gambar 6. A: 3 mm, B: $1 \mathrm{~mm}$. 


\section{Macrobrachium latidactylus}

Macrobrachium latidactylus memiliki ciri morfologi berupa gigi rostral pada dorsal kecil dan rapat berjumlah 15-17, gigi di belakang mata berjumlah 3-4, gigi rostral pada ventral berjumlah 3-4, post antenular carapace margin lurus. Dasar pada bagian rostrum rendah serta pada kaki jalan kedua terdapat carpus yang membesar. Morfologi $M$. latidactylus yang didapatkan di Sungai Batambean sesuai dengan yang dideskripsikan Chace and Bruce, (1993), rumus gigi rostral 3-5 + 10-11/2-5, margin lateral lurus serta kaki jalan kedua memiliki ukuran dan bentuk berbeda. Macrobrachium latidactylus dilaporkan dari daratan utama Pulau Sulawesi yaitu dari Sungai Giliana Morowali Utara (Laewa dkk., 2018), Kwandang, Bantimurung, sungai dekat Palopo dan sungai dekat Pare-Pare sedangkan laporan dari pulau satelit sekitar daratan utama Pulau Sulawesi yaitu dari Pulau Talaud (Holthuis, 1950).

Spesies ini adalah jenis udang yang tersebar luas mulai dari Indonesia, Malaya, Filipina, Taiwan, Cina Selatan, Sri Lanka sampai Pulau Ryukyu (Chace and Bruce, 1993; Eguia et al., 2009).

\section{Caridina gracilipes}

Caridina gracilipes memiliki ciri morfologi yaitu rostrum panjang melebihi scaphocerit serta melengkung ke atas. Gigi rostral dorsal, jarang berjumlah 11-15, gigi di belakang mata berjumlah 2-3 dan gigi rostral ventral jarak antar giginya rapat berjumlah 9-16. Menurut Chai and Shokita (2006), ciri morfologi C. gracilipes rostrum panjang melengkung ke atas mencapai atau melebihi scaphocerite. Rumus gigi rostral yaitu $1-3+11-27+$ 1-3 / 8-18. Caridina gracilipes dilaporkan dari daratan utama Pulau Sulawesi yaitu dari Sungai Batusuya, Sulawesi Tengah (Dwiyanto dkk., 2018).

Spesies ini adalah jenis udang yang tersebar luas mulai dari Indonesia (Sulawesi), Taiwan, China sampai Filipina (Cai and Shokita, 2006).

Dari hasil penelitian ini dapat disimpulkan bahwa komposisi jenis udang air tawar di Sungai Batambean terdiri dari empat spesies, yaitu Macrobrachium australe, $M$. equidens, $M$. latidactylus dan Caridina gracilipes. Kesemua spesies tersebut adalah udang air tawar yang bersifat amphidromy yang dalam menyelesaikan siklus hidupnya masih membutuhkan air laut atau air payau.

\section{Ucapan Terima Kasih}

Penulis pertama mengucapkan terima kasih kepada Dr. Ir. Daisy Wowor, M.Sc (Kurator Laboratorium Museum Zoologi LIPI) telah membimbing penulis dalam melakukan identifikasi udang air tawar, dan kepada Bapak Ujang Nurhaman (Teknisi Lab. Crustacea Museum Zoologi LIPI) yang telah mengajarkan teknik sampling selama penulis mengikuti program magang di Museum Zoologi LIPI. Terima kasih penulis juga ditujukan kepada Aswandi, Fazlur Rahman, Moh. Basit, Rizki Ramadhana Takdim, Ni Luh Setiawati, Dewi Santika dan Preis Fransiska Malino yang telah membantu dalam proses pengambilan sampel di Pulau Labobo.

Sebagian penelitian ini didanai oleh Anggaran Penelitian Hibah Berbasis Kompetensi berdasarkan Surat Keputusan Nomor 3/E/KPT/2018 dan Perjanjian Kontrak Nomor 283.a/UN28.2/PL/2018. Karena itu penulis kedua mengucapkan terima kasih kepada Direktorat Penelitian dan Pengabdian kepada Masyarakat (DP2M) Kemenristik Dikti.

\section{Daftar Pustaka}

Cai, Y, and Shokita, S., 2006, Report on a collection of freshwater shrimps (crustacea: decapoda: caridea) from the Philippines, with descriptions of four new species. Raffles Bulletin of Zoology, 54(2), 245-270.

Cai, X., De Grave, S. \& Klotz, W., 2013, Caridina gracilipes. The IUCN Red List of Threatened Species 2013: e.T198028A2509110. http://dx.doi.org/10.2305/IUCN.UK.20131.RLT S.T198028A2509110.en. Downloaded on 10 May 2019.

Chace, F. A., and Bruce, A. J., 1993, The Caridean Shrimps (Crustacea: Decapoda) of The Albatross-Philippine Expedition, 1907-1910, Part 6: Superfamily Palaemonoidea, Smithsonian Institution Press, Washington.

D'Abramo, L. R., Tidwell, J. H., Fondren, M, and Ohs, C. L., 2006, Pond production of the freshwater prawn in temperate climates. United States Department of Agriculture. Southern Regional Aquaculture Center (SRAC) Publication No. 484.

De Grave, S., Wowor, D. \& Ayhong, S., 2013, Macrobrachium equidens. The IUCN Red List of Threatened Species 2013: e.T198164A2514114. http://dx.doi.org/10.2305/IUCN.UK.20131.RLT 
S.T198164A2514114.en. Downloaded on 10 May 2019.

De Grave, S., Wowor, D. \& Page, T., 2013, Macrobrachium australe. The IUCN Red List of Threatened Species

2013:

e.T198235A2517134.

http://dx.doi.org/10.2305/IUCN.UK.20131.RLT

S.T198235A2517134.en. Downloaded on 10 May 2019.

De Grave, S., Wowor, D., Ayhong, S. \& Shy, J., 2013, Macrobrachium latidactylus. The IUCN Red List of Threatened Species 2013:e.T197860A2503002.

http://dx.doi.org/10.2305/IUCN.UK.20131.RLT S.T197860A2503002.en. Downloaded on 10 May 2019.

Dwiyanto, D., Fahri, dan Annawaty., 2018, Keanekaragaman udang air tawar (Decapoda: Caridea) di Sungai Batusuya, Sulawesi Tengah, Indonesia. Scripta Biologica, 5(2): 6571. Doi: 10.20884/1.SB.2018.5.1.821

Eguia, M. R., Dejarme, H. E., Rosario, W, R., Roxas, E, C., Wowor, D., 2009, Philippine Freshwater Prawns (Macrobrachium spp.). Tigbauan, lloilo, Philippines: Southeast Asian Development Center (SEAFDEC) Aquaculture Department.

Holthuis, L. B., 1950, The Decapoda of the Siboga expedition. Part 10. The Palaemonidae collected by the Siboga and Snellius Expeditions, with remarks on other species. I. Subfamily Palaemonidae. Siboga-Exped. Monogr, 39(9): 1-268.

Laewa, N. H., Fahri, dan Annawaty., 2018, Udang air tawar Macrobrachium latidactylus (Decapoda, Caridea, Palaemonidae) dari Sungai Gililana, Morowali Utara, Sulawesi, Indonesia. Natural Science: Journal of Science and Technology, 7(2): 205-216.
McDowall, R. M., 2007, On amphidromy, a distinct from of diadromy in aquatic organism. Fish and Fisheries, 8: 1-13.

Merquet, G., 1991, Freshwater crustaceans of French Polynesia: taxonomy distributions, and biomass (Decapoda). Crustaceana, 61: 125140.

New, M. B., 2002, Farming Freshwater Prawns. A Manual for the culture of the giant river prawn (Macrobrachium rosenbergii) Roma: FAO Press.

Rahmi, Annawaty, dan Fahri., 2016, Keanekaragaman udang air tawar genus Caridina di Sungai Tinombo Kecamatan Tinombo Kabupaten Parigi Moutong Provinsi Sulawesi Tengah. Natural Science: Journal of Science and Technology, 5(2): 199-208.

Valenti, W. C., Daniels, W. H., New M. B. and Correia E. S., 2010, Hatchery Systems and Management. In: New, M. B., Valenti, W. C., Tidwell, J. H., D’Abramo, L. R., Kutty, M. N (eds). Freshwater prawns. Biology and Farming. Wiley-Blackwell, Oxford, England.

von Rintelen, K., Karge, A. and Klots, W., 2008, News from a small island-first record of a freshwater shrimp (Decapoda, Atyidae, Caridina) from Peleng, Banggai Islands, Indonesia. Journal of Natural History, 42:2233-56.

Welch, E., B. and Lindell, T., 1980, Ecological Effect of Waste Water. London: Cambridge University Press.

Wowor, D., Cai, Y. and Ng, P. K. L., 2004, Crustacea: Decapoda, Caridea. In: C. M. Yule, \& H. S. Yong (eds.), Freshwater Invertebrates of the Malaysian Region. Academy of Sciences Malaysia (pp 337-357), Kuala Lumpur. 